\title{
Assessment of the Capacity of TVET and University Hospitality Schools in offering Food Safety and Hygiene Training in Kenya
}

\author{
Monica A. Wandolo, Prof. Douglas Ndiritu, Dr. Rosemarie Khayiya, Dr. Beatrice W. Mugendi
}

School of Hospitality and Tourism Management of Kenyatta University, Kenya.

\begin{abstract}
The purpose of this study was to assess the capacity of TIVET and University hospital schools in offering food safety and hygiene training in Kenya. The major areas of focus were the general availability of basic equipment, whether the available equipment were modern, extent of use of available equipment and workshop organization including drainage. A total of 671 respondents participated in the study (Comprising 249 from universities, 250 from Institutes of Technology, 64 from Polytechnics and 128 from Technical Institutions). Primary data sources included using structured questionnaires, taking photographs, oral interviews, observation check list and focus group discussions. Secondary sources, on the other hand, involved retrieving information from desk research where journals, books and other relevant literature were obtained. Both descriptive and inferential statistics were used to analyze the quantitative data while content analysis was used to analyze the qualitative data. The analyzed data were presented in terms of graphs and tables. The findings revealed that in the two categories of institutions, equipment/tools in universities were relatively higher in number compared to the other categories. In addition, not all the available tools were modern. It was observed that only $78 \%$ of the available tools were modern while $19 \%$ were not. This finding revealed that there was underutilization of available facilities in the institutions. A summary of various aspects of capacity of institutions in providing training on food safety and hygienic practices and adopting proper hygienic practices revealed that universities had a high capacity (63.5\%) relative to the other categories. On the other hand, the lowest capacity level was observed in institutes of science and technology, which had $46.4 \%$. The findings further revealed that some institutions were wellprepared in terms of equipment and facilities, while the majority were not. Observation revealed that most of the workshops used, particularly in TVET institutions, were originally used for other purposes such as classrooms, home economics laboratory or were stores converted to production workshops. As a result, such institutions lacked basic equipment. The study concluded that TIVET and Universities had inadequate facilities and resources required to offer food safety and hygiene training courses. It was recommended that ministry of education should to identify a monitoring team to visit hospitality training workshops to assess the capacity in terms of infrastructure, facilities and equipment to determine the level of requirement in every institution. This would pave way for the upgrading of the facilities to a level that they would offer adequate training to the enrolled students.
\end{abstract}

Key Words: Food safety and hygiene, capacity of learning institutions, safety and hygiene training

\section{Introduction}

According to a report by World Health Organization (2003), the magnitude of Food-Borne Diseases (FBDs) caused by contaminated food and water significantly contributed to a myriad of health problems. FBDs were said to be on the increase despite adoption of vast measures to curb food-related illnesses. The Centre for Disease Control and Prevention (CDC, 2005) attributed this upward trend to increased multiplication rate of disease-causing microorganisms and exposure to 00 levels of toxins from industrial effluents. CDC (2005) further added that poor hygiene practices, inadequate cooking, improper holding temperatures, use of contaminated equipment and poor personal hygiene contributed significantly to the spread of FBDs. Though symptoms of FBDs varied from one individual to another or from place to place, common symptoms ranged from mild gastroenteritis to life-threatening neurologic, hepatic, and renal syndromes (Hughes, 2000). 
Further reports by CDC (2005) indicated that more than 250 different food-borne diseases have been identified and most of the illnesses are caused by microbial contaminants. Some of the most common disease-causing microbes included Escherichia Coli 0157:H7, Salmonella, Campylobacter and Staphylococcus among others (CDC, 2004). Among these groups of microorganisms, some were capable of mutating and re-emerging as new organisms. This feature, frequently observed in Salmonella enteritidis and Escherichia-coli 0157:H7, interfered with the process of reducing FBDs. In the US, for example, a nationwide survey conducted between 1998 and 1999 by the CDC found that microbiological contamination was the number one cause of FBDs followed closely by chemical contamination. Food-related infections were said to constitute a critical health problem in both developed and developing countries (Dugassa, 2007). Further reports indicated that food- borne illness was a major cause of personal stress, preventable death and avoidable economic burden in USA (Mead, et al., 1999). It had also been estimated that food-borne diseases causes 76 million illnesses, 325,000 hospitalizations and 5000 deaths each year (Anding, 2001). Additionally, the annual cost of FBDs in terms of pain and suffering, reduced productivity and medical cost is estimated to be between $\$ 10$-83billion (Anding, 2001).

Apart from the USA, other developed countries also experienced the burden of FBDs. In Turkey, for instance, a total of 23,010 cases of dysentery were reported in 1997 (Aycikel, 2007). In Emilia-Romagna, a single region in Italy, 1564 episodes of food-borne diseases were reported between 1988 and 2000 (Legnani, 2004). A national survey done by the British government in 2009 revealed that outbreaks of food poisoning had serious financial and social implications (Christopher, 2010). The survey further added that Salmonella alone caused 1939 food-related illnesses (Acheson, 2011). On the same vein, indicated that about one million people suffer from food poisoning every year at an estimated cost of $\$ 1.5$ million annually (Acheson, 2011). Another observation by Rona Ambrose, Minister of Health in Canada (2014), also reported that although Canada boasted of the safest and healthiest food safety systems in the world, the Government was still committed to strengthening food safety by giving tough penalties and cracking down those that did not comply with food safety measures.

In developing countries, particularly in most African countries, a change in socio-economic setting had resulted in multiple food safety challenges (Green, 2003). Green pointed out that between $70 \%$ and $90 \%$ of employees in Africa were in the food trade. These traders were said to significantly influence the prevalence of FBDs in their respective countries. Green (2003) added that availability, distribution and maintenance of adequate supply of portable water and nutritious food were the major challenges to most of these countries. Moreover, inadequate sanitation and physical facilities were said to contribute to lower aesthetic standards, resulting to contaminated food and water (Green, 2003).

According to Dugassa (2007), the burden of food-borne illness in developing countries was significant, and was said to be in a worse condition than developed countries due to inadequate and poorly developed food safety structures and policies. A report by FAO and WHO (2005) indicated that the challenges of food safety in Africa were precipitated by poor food safety systems, lack of systematic surveillance and structural organizations which were viewed as weak and could not protect human health. Besides, there was underdeveloped human resource and insufficient capacity to determine the prevalence and magnitude of the problem. According to Adams (2003), developing countries experienced the challenges of widespread poverty, rapidly growing population and large-scale migration to already overcrowded cities leading to poor sanitary conditions. He further indicated that about 2.6 billion people in developing countries lacked even a simple pit latrine, and about 1.1 billion had no access to portable water. Adams (2003) therefore concluded that food safety was a big challenge due to lack of facilities for hygienic preparation and storage of food.

Kenya, like other countries was not exempted from the burden of FBDs. According to Abegaz (2007), up to $70 \%$ of all diarrhoeal episodes were attributed to ingestion of contaminated food and water. This study viewed training intervention of food handling personnel as a solution not only in Kenya but also in Africa and other developing countries struggling with food safety challenges. It was upon this backdrop that this study aimed assessing the capacity of TVET and university hospitality schools in offering food safety and hygiene training in Kenya. 


\subsection{Training in Relation to Food Safety and Hygiene}

Training plays an important role in any career and is expected to result in a change of behaviour, attitude and skill of the participants. A report on quantitative survey carried out in Australia on training trends on food safety management indicated that effective education and training programmes provide the best way of improving safety awareness among food handlers (Linda, Roberts \& Deery, 2004). The report further indicated that there was need to train, especially food managers, on safety and hygiene in order to improve their capacity to deal with issues related to food safety. A similar study in Thailand also pointed out that governments needed to formulate food safety policies that would include educating senior managers on the benefits of safe food.

While exploring the importance of education as a measure towards curbing FBDs, Raymond (2006) reported that education intervention for consumers was an important step in minimizing food-related illnesses. This claim was important since inadequate implementation of food safety practices in the homes was also viewed as a contributing factor to food-borne diseases. Raymond (2006) further proposed simple hygiene measures such as hand washing as a way of reducing contamination by at least $87 \%$ and reducing cross contamination by $85 \%$, as well as proper cooking which reduced contamination by $77 \%$. Based on reports from these surveys, education and training were considered key in ensuring that appropriate food safety measures were employed. Douglas (2011) however, noted that many institutions were not adequately managing food safety despite basic training of employees. He recommended that to overcome this challenge, institutions could organize mandatory training for all persons in food service outlets and ensure strict implementation of food safety management systems.

In Kenya today, an increase in population and thirst for training opportunities has significantly contributed to the growth of training institutions offering food production related courses at degree, diploma, craft and artisan levels. The Universities and tertiary institutions offer these courses at different levels. The tertiary institutions that offer these courses fall under Technical and Vocational Education and Training (TVET) colleges. The increase of TVET colleges have been occasioned by the need to alleviate high unemployment rate among the youths by producing graduates who are tailor made for self-employment. As a result, between 2009 and 2012, the government upgraded 11 TVET institutions to centres of excellence by rehabilitating the workshops and improving their facilities. At the same time, upon realization that there was still need for more specialised managerial skills, the universities introduced hospitality courses to offer degree and diploma programmes. This gap may have been aggravated by high demands for higher skills for particular disciplines, including hospitality. The rapid increase of University hospitality schools and TVET colleges has raised a lot of concerns as to whether these institutions have met the threshold standards for hospitality training.

According to the Sessional Paper No. 1 (2005), the objective of TVET and University hospitality schools was to train professionals who could apply scientific knowledge in solving any environmental problems in the industry. This study therefore sought to assess the strengths and weaknesses of both institutions with the view of improving their weak areas. The study also sought to establish whether university hospitality schools have put up better food safety training measures than TVET Colleges or otherwise. The study intended to come up with ideas and strategies, which would improve food safety training. In addition to improving the existing situation, the study also intended to find means of reinforcing and integrating theory with practice on food safety and hygiene, by recommending policies that would safeguard their operations. Upon completion of their training, graduates from TVET and Hospitality Schools work in the hospitality industry as managers, assistant managers, chefs, waiters, supervisors and food production assistants. An effective training therefore would have an impact in the entire hospitality industry across the country.

\subsection{Problem Statement}

Food poisoning is on the increase as a result of consumption of unwholesome food. Food handling personnel are assumed to be responsible for most illnesses as a result of poor handling behaviour. Angelilo, Vigiani, Rizzo, and Bianco (2000) argued that although food handling personnel played an important role in producing food for consumption, they were likely to contaminate the food by introducing pathogens in the process of preparation, production, processing, distribution and service. Studies by Akonor and Akonor 
(2013) indicated food safety was a public health problem associated with consumption of food and water, mainly triggered by improper food handling practices. Studies conducted by Mulan and Wong (2006) reported that an estimated 5.4 million Australians got sick annually from eating contaminated food and that up to $20 \%$ of the illnesses were suspected to originate from inappropriate handling behaviour. In fact, the WHO (2007) also recorded that up to $30 \%$ of individuals in developed countries suffered illnesses related to consumption of food and water hence pointing out that food safety was a major global catastrophe (WHO, 2007).

Kenya is not an exception. A number of FBDs triggered by improper food handling practices have affected the Kenyan population over the years. Abegaz (2007) noted that the most prevalent diseases in Kenya in the year 2004 alone were typhoid, which affected 643,151 people, dysentery, which affected 600,660, and gastroenteritis, which affected 722,275 people. Abegaz also added that aflatoxin poisoning affected 323 and brucellosis 198, while 68 persons were victims of cholera. Based on the frequency and location of the diseases, the report further indicated that some of the FBDs were seasonal and subsequently, required urgent intervention. Other reports indicated that E.coli alone caused an estimated 73,480 illnesses, leading to 2,168 hospitalizations and 61 deaths annually (Rangel, Sparling, Crowe, Griffin and Swerdlow, 2005).

Globalisation, rapid urbanisation, increase in population and change of eating habits has led to a significant increase in the growth of the food service outlets in Kenya. Despite the economic benefits of these sectors, they are viewed as potential hazards especially when food is not hygienically prepared. There is therefore a critical need to provide adequate training for food handling personnel, to ensure that FBDs caused by improper food handling practices are eradicated. This study identified that in Kenya, food handling practices are taught, but when it comes to practice, the ballgame changes. Accordingly, Mortlock, Peters \& Griffith, (2009) observed that efficacy of training in terms of changing behaviour and attitudes to food safety was questionable. However, Clayton and Griffith, (2004) observed that only knowledgeable trained and skilled employees followed proper procedures when handling food. In essence, if food handling personnel are trained on proper food handling practices, there is a likelihood that FBDs will take a decline trend. It is upon this background that this study sought to assess the capacity of TVET and university hospitality schools in offering food safety and hygiene training in Kenya.

\section{Literature Review}

This Section presents the relevant literature on hospitality and food-service industry and the general overview of Technical and Vocational Education and Training (TVET) and University Hospitality Institutions in Kenya. It also presents literature on training on food safety and hygiene practices, knowledge and practices of food handlers, food safety and personal hygiene of the handlers and food safety and employee related characteristics

\subsection{Hospitality and Food-Service Industry}

According to Dittmer (2000), the term hospitality was derived from the Latin word Hospice, meaning to receive a guest. O'Gorman (2007) argued that hospitality principally focused on a host who received, welcomed and catered for the needs of the guest who was temporarily away from home. Such needs included food and shelter, among others. Development of hospitality depended on increase of population, economic growth of cities and good transport systems. Development of transport systems for instance, allowed movement of people from one place to another and consequently enhanced interactions, which led to the development of motels, inns and hotels. The hotels later developed into more spacious chains with cuisines designed to meet the customers' needs (O'Gorman, 2007). The trend prompted the construction of hotels near airports to provide hotels and conference facilities. The inventions of the modern technology in the 1990s made an impact on the hospitality industry leading to expansion of hotels to cater for more enlightened customers. This created need for trained personnel and soon new techniques and methods of service delivery were devised (Levy, 2009).

Kenya is known to have experienced remarkable advancements in the hotel industry. Today, hospitality industry is one of the largest foreign exchange earners, with the industry having contributed to approximately $10 \%$ of the gross domestic product (GDP). Despite this significant contribution, the industry was recorded as having faced many challenges in satisfying the diverse nature of the hospitality and tourism 
industry. To overcome this challenge, the hospitality industry in Kenya was required to engage professionals with the required competence to address the problem, and this could only be achieved through appropriate context - based, need-driven training and education. It is upon this backdrop that TVET and hospitalitytraining colleges were established.

\subsection{Technical and Vocational Education and Training (TVET) and University Hospitality Institutions}

The term TVET as used in this study, referred to 'those aspects of the educational process involving, in addition to general education, the study of technologies and related sciences and the acquisition of practical skills, attitudes, understanding and knowledge relating to occupation in various sectors of the economy (ILO, 2011). In this description, the International Labour Organization (2011) implied that the institutions incorporated technical education, industrial education, vocational education, apprenticeship and on-job training.

ILO (2012) further reported that one billion young people, the majority from low- and middle-income countries (LMICs) were predicted to reach employment age within the next decade. This prediction posed a threat to the severely limited opportunities for integrating youth into the labour market. This worsening youth unemployment crisis led to the development of Technical, Industrial and Vocational Education and Training (TIVET) institutions. However, as reported by the African Union (2007), the institutions had previously been established but collapsed since their importance had not been clearly understood in several regions globally. The collapse was also attributed to the neglect by the World Bank and donor agencies. Nevertheless, with increasing demand for better skills in the global knowledge-based economy, TVET institutions came back on the development agenda after years of neglect. This renewed focus on the potential of TIVET to equip the youth with abilities to seize available work opportunities aimed at reducing global poverty level and to improve social stability. Consequently, there was growing investment in TIVET institutions since 2000 (African Union, 2007). The same trend was observed in Kenya. The past decade saw TIVET institutions being included in the development agenda and as a result; several TIVET institutions were established in several parts of the country. More recently, the Ministry of Education, Science and Technology renamed TIVET to TVET (Technical and Vocational Education and Training).

\subsection{Training on Food Safety and Hygiene Practices}

WHO (2007) identified the training of food handlers as one of the most indispensable interventions in the prevention of food-borne diseases. McLauchlin and Little (2007) defined food hygiene education as the 'process of acquiring knowledge and training for the prevention and control of food-borne disease.' Education and training was believed to get the trainee informed to be able to perform given tasks effectively and with understanding. In Kenya this responsibility was given to the Ministry of Higher Education, Science and Technology (MOEST). The Ministry of Education, Science and Technology (2012) articulated the primary task of higher education as being to cultivate high level innovative talent and standards that embraced proper food safety and hygienic practices. It added that in hospitality training, food safety was a priority foundation unit that was important in imparting knowledge and skills in food handling behaviour. As Knowles (2002) explained, the recipients of training were expected to have a higher level of understanding at the end of the training.

Food and beverage production service and food hygiene were considered as public health professional basic course. In fact, appropriate food hygiene training and enactment of safe food handling practices learnt during training were critical elements in the control of food-borne illnesses. Toh and Birchenough (2000) observed that there was a strong correlation between knowledge and positive food handling practices. This report reinforced the importance of conducting a preliminary assessment of training needs and evaluating the effectiveness of the training as suggested by Rennie (1999). Rennie (1999) further reiterated that knowledge gained was intended to bring about behaviour change and as such, the learners had to be motivated. Besides, the correct environment had to be created so that the trainees could apply the relevant skills to the work experience that had to be rewarded with certificates which was relevant of the training. Rennie (1999) came up with an illustration as shown below. 


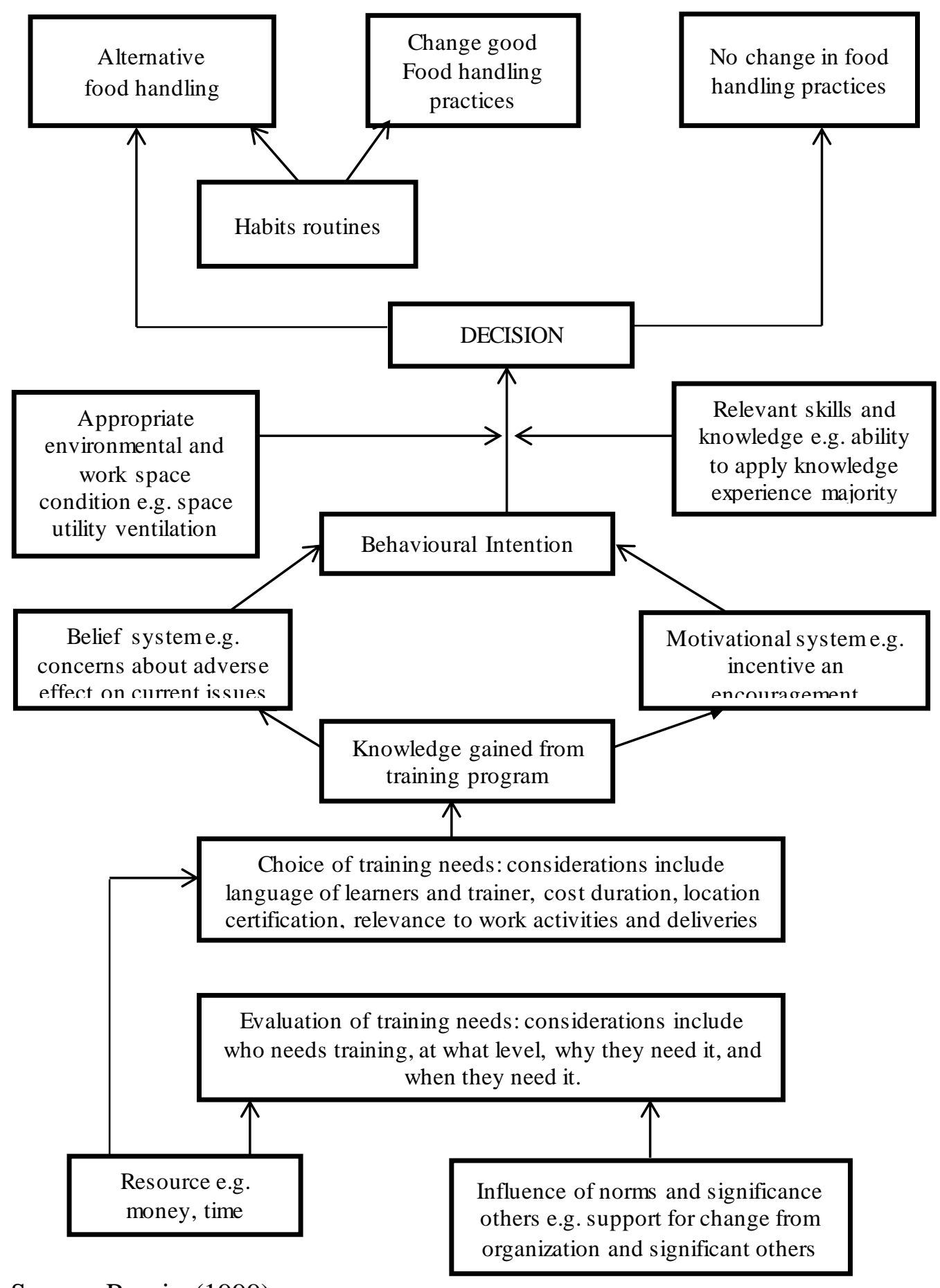

Source: Rennie (1999)

Figure 1:- Food Safety Model (Rennie, 1999)

The model was viewed as a way of improving food businesses, which would, in effect, reduce food-borne illnesses. There was an implied assumption that such training would lead to changes in behaviour based on the Knowledge, Attitudes and Practices (KAP) model (Seaman and Eves, 2006). This model was criticized by Griffith (2001) for its limitations. Griffith argued that knowledge alone was insufficient to trigger preventive practices and that other mechanisms were needed to motivate action and generate positive attitudes. In an evaluation of food hygiene training, Egan, Raats, Grubb, Eves, Lumbers, Dean and Adams (2007) observed that although there was positive response towards knowledge of good hygiene, knowledge alone did not result in changes in food handling practices, and as a result change of behaviour also played an important role. Tripney (2007), on the same vein, postulated that effective and relevant food hygiene training delivered with the support of the government re-enforcement could have some effect on food handlers' behaviour that would ensure that safe working practices were sustained. Another study by Yiannas (2007) observed that hands-on training on good hygienic practices (GHP) would contribute to retention of 
important food safety issues as articulated by the Chinese proverb: I hear and I forget, I see and I remember, I do and I understand (Yiannas, 2007).

Studies carried out by Griffith (2011) linked the behaviour of food handlers to organizational culture and food safety management systems adopted by particular organizations. Benjamin (2011) noted that despite extensive investment in food handlers' training, the programmes used were inconsistent and were rarely evaluated for efficacy by the stakeholders. As a result, Global Food-borne Network (GFN), a building capacity for control and prevention of FBD infections resolved to develop international training courses to build technical capacity and quality systems. These systems were crucial in the laboratory to test FBD and identify pathogens. GFN has since established 17 training sites around the world and has conducted over 65 training courses in Chinese, English, French, Portuguese, Spanish and Russian languages for microbiologists. This has resulted in more than 80 countries being able to provide data of over 1.5 million human-related microorganisms, especially salmonella.

\subsection{Knowledge and Practice of the Food Handlers}

A study by Rodríguez and Gregory (2005) revealed that an effective training programme assessed whether participants acquired new skills during the training, and whether the newly acquired skills were transferred to the job setting. The report further indicated that food safety training was recommended for all cadres of staff including junior food-service staff, supervisors and managers who needed to know the dangers of foodborne illnesses and their prevention. Another study by (Egan et al., 2006) also observed that effective training depended on both attitude of the management and their willingness to provide resources needed for implementation of food safety systems. According to Birchenough (2000), there was a strong correlation between knowledge and food handling practices. Earlier studies on performance of individuals indicated that food safety knowledge increased with age and practice. Nurul (2008) suggested that training and motivation needed to be provided to encourage food handlers to practice appropriate attitude and procedures when working in the food arena.

By the same token, another study conducted by Coleman and Roberts (2005) observed that for food safety delivery systems to be effective, the prevailing food safety beliefs, knowledge and practices of food handlers had to be assessed, to determine what was needed to change their attitude. More importantly, Howells, Roberts, Shankling, Pilling, Branson and Berret (2008) postulated that there was a correlation between positive behaviours (attitudes) and continued education of food handlers towards sustenance of safe food handling practices. Howells et al. $(1996 ; 2008)$ indicated that approximately $97.0 \%$ of foodborne outbreaks were as a result of improper food handling practices in food service outlets. On the other hand, Ehiri and Moris (2001) pointed out that knowledge alone was not sufficient to promote positive attitudes and safe behaviour among food handling personnel. Ehiri and Moris (2001) also observed that attitude was an important factor that could not be ignored if FBDs were to be minimized.

\subsection{Food Safety and Personal Hygiene of the Handlers}

A microbiological study of open, ready-to-eat, prepared salad vegetables from retail catering premises by Sagoo, Little and Mitchell (2003) identified a direct relationship between food hygiene training and practice of food safety procedures. Another study of ready-to-eat food from retail premises in North Eastern England by Richardson and Stevens (2003) also indicated that members of staff who practiced poor personal hygiene could contaminate food items with infected excreta, pus, respiratory drippings or other infectious discharges. This claim implied that food handlers were the major sources of contamination either as carriers of pathogens or through poor hygienic practices (Kaferstein, 2003). The study further suggested that food handlers could carry microbial pathogens on their skin, hair, hands, digestive systems or respiratory tracts. As a result, the report asserted that it was imperative for the staff to understand and follow basic food hygiene principles to avoid unintentional contamination of foods, water supplies and/or equipment used during the processing of food (Richardson and Steven, 2007).

Sneed, Strohbehn and Gilmore (2004) conducted another study on food safety practices and implementation of HACCP programme in facilities in Iowa and identified a number of food safety practice concerns. They observed that hand washing was inappropriately done and food handlers had no effective hair restraints. The 
study also noted that food temperature monitoring and recording were infrequent and sanitizer concentration used was not checked regularly. The study concluded that employees in foodservice operations had sufficient food safety knowledge and positive attitudes toward food safety but were not following the correct procedures, an indication that there was need to improve food safety practice (Sneed et al., 2004).

\subsection{Food Safety and Employee-Related Characteristics}

Apart from personality related behaviours, Bertin (2009) also observed that certain employee-related characteristics such as poor educational level, low socio-economic level, rapid staff turnover, literacy barriers and poor motivation due to low pay also contributed to poor professional performance at work. Bertin found that food handlers had a very important role in preventing contamination during food preparation and distribution and this responsibility became even greater in hospitals.

Other studies used for testing effectiveness of hygiene education pointed out that hygiene knowledge alone was not sufficient in improving hygienic attitude and practices of food handling personnel. The studies further indicated that discrepancies still existed between hygiene, knowledge and practices (Park, Kwak and Chang, 2010). One explanation for the discrepancy between food safety knowledge and practice was the barriers experienced in the food-service establishment that could prevent food handlers from implementing practices such as good hand washing in the restaurants (Green and Selman, 2005). The duo observed that availability and accessibility of hand washbasins was a major concern followed by peak time pressure during operations. Moreover, high volume of business, stress, lack of accountability, lack of equipment, type of restaurant and inadequate food handler training were considered as critical barriers mentioned by participants in other studies (Pragle, Harding, and Mack, 2007). Another significant contribution by Clayton, Griffith, Price and Peters (2002) recorded that time was a major factor that barred correct practices of food safety.

\section{Methodology}

Descriptive cross sectional survey design was used in the study. The design combined both qualitative and quantitative data collection and analysis techniques. Quantitative data was derived from questionnaires while qualitative data was generated from interview schedules. The design was therefore appropriate for the study since this study was interested in establishing the facts as they are in relation to food and hygiene practices in training institutions. The study was carried out in TVET institutions offering diploma programs and university hospitality schools offering degree programs in Kenya. The TVET institutions included Polytechnics, Institutes of Science and Technology and Technical Training Institutions (TTIs). There were over 44 TVET institutions and over 10 university hospitality schools in Kenya that offered courses in food and beverage production and service. The inclusion criteria consisted of all third year students in TVET institutions who were almost graduating, and third year students from Universities who had covered three quarters of the course-work. First and Second years were excluded from the study as they had not had enough exposure in food production or food and beverage service. Heads of Departments of these courses were also included, as they represented their various institutions. A total of 671 respondents participated in the study (Comprising 249 from universities, 250 from Institutes of Technology, 64 from Polytechnics and 128 from Technical Institutions).

In selection of respondents, both probability and purposive sampling techniques were used. Probability sampling technique was used in selection of student-respondents. In this case, each target student-respondent was pre-assigned some chance of being included in the sample. This technique was used since it minimized biases in sample selection. As one method of probability sampling technique, lottery method was used to identify specific sample units. This was done using identical cards where numbers were written and cards drawn at random. Population unit whose identification number corresponded to a drawn card was selected. This procedure was repeated for all the sample units. On the other hand, purposive sampling technique was used in the selection of staff-respondents. This technique was used since it facilitated the provision of focused information, besides being able to save time and money. Both primary and secondary data were used in the study. Primary data sources included using structured questionnaires, taking photographs, oral interviews, direct observation and focus group discussions. Secondary sources, on the other hand, involved retrieving information from desk research where journals, books and other relevant literature were obtained. 
Questionnaires were used to collect data from students and lecturers while interview schedules were used to collect data from departmental heads. Both descriptive and inferential statistics were used to analyze the quantitative data while content analysis was used to analyze the qualitative data. The analyzed data were presented in terms of graphs and tables.

\section{Findings Of The Study}

This section presents the findings of the study on the capacity of TIVET and University hospital schools in offering food safety and hygiene training in Kenya. The major areas of focus were institutions' equipment and sanitary facilities. The study also looked at how prepared institutions were in implementing proper measures that ensured maintenance of high hygienic standards. In so doing, the researcher considered the following aspects of suitability and capacity of the institutions: general availability of basic equipment/tools, whether modern mechanical, electrical and large equipment/tools are available, extent of use of available equipment and space available and workshop organization including drainage.

\subsection{General Availability of Equipment/Tools}

Several equipment/tools were identified and respondents asked whether the equipment/tools were available in their institutions or not. An average of the response category 'Available' was computed and crosstabulated against the institutions.

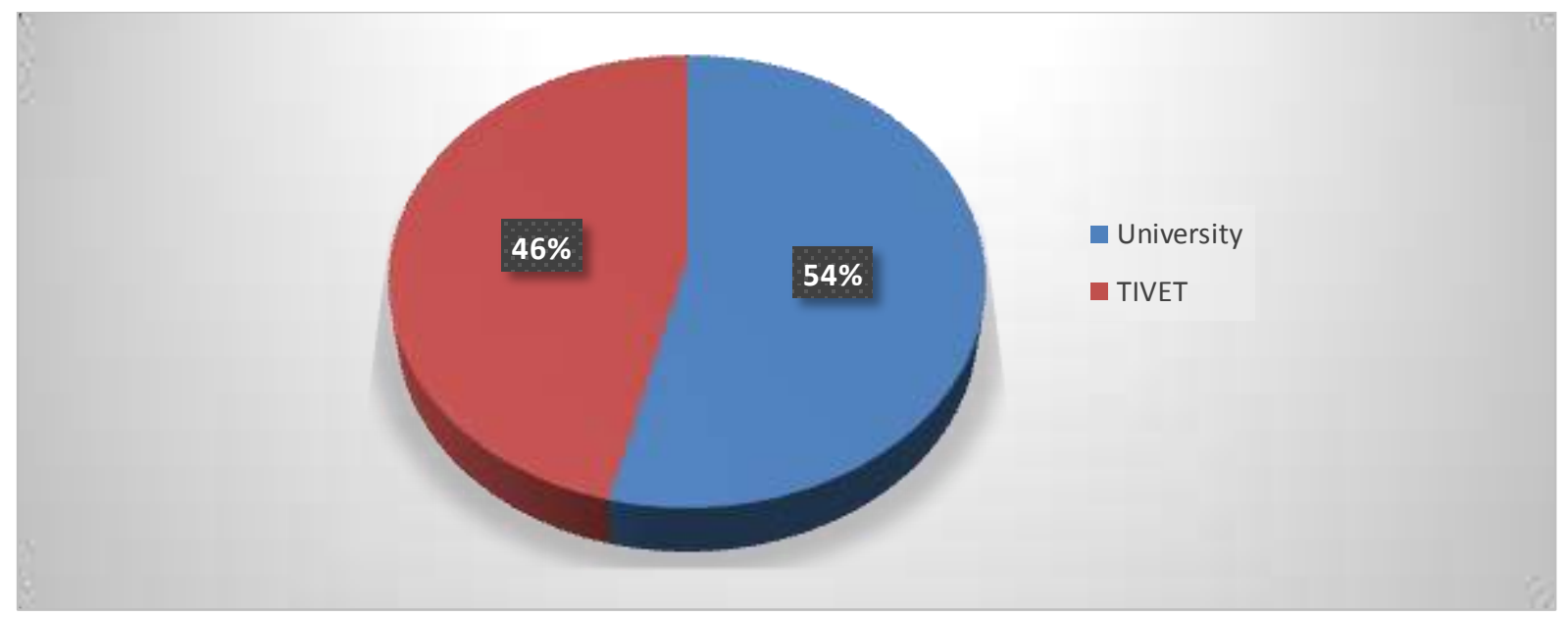

\section{Figure 2:- General Availability of Equipment/Tools}

Figure 2 indicated that though there was almost equality in the availability of basic equipment/tools in the two categories of institutions, availability of various equipment/tools in universities were, however, relatively higher than TVET colleges. This was attributed to the fact that most university hospitality schools are relatively new and new equipment were purchased before undertaking the training. However, TVET colleges are old institutions and some of their equipment could be worn out, broken and not replaced immediately. The researcher further examined whether the available tools were modern. Responses in this question were summarized as shown in Figure 3. 


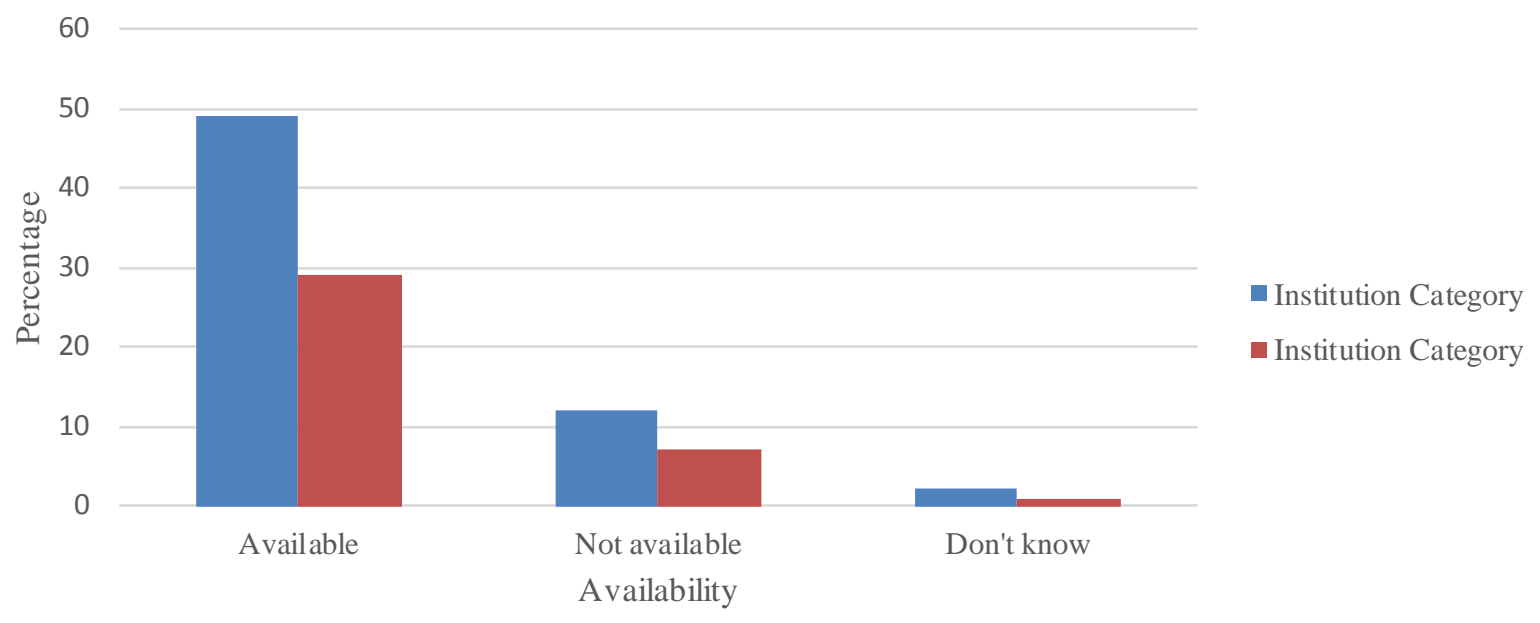

\section{Figure 3:- Availability of Modem Equipment}

Figure 3 revealed that majority of respondents $(78 \%)$ agreed that the equipment/tools available were modern. This was a good finding since it showed that most institutions used tools/equipment which is service-able. However, a significant proportion of respondents also agreed that they did not use or have modern tools/equipment. This was vital observation since it implied that dilapidated and old tools/equipment were still being kept in the institutions and these could pose a challenge to the industry of space in the workshops.

The study found out that quite a number of institutions had very old equipment which were also inadequate to cater for the number of students enrolled. Use of dilapidated facilities, equipment and tools jeopardized adoption and implementation of food safety and hygiene practices in the training institutions. In addition, old equipment harboured rodents and other insects such as cockroaches. To check on the differences in availability of modern equipment in the institutions, Kruskall Wallis Test was performed between institution category and availability of modern equipment/tools. The result was summarized as shown in Table 1 .

Table 1:- Kruskall-Wallis Test on Institution Category and Availability of Modem Equipment

\begin{tabular}{llccccc}
\hline & Modern Equipment & $\mathrm{N}$ & Mean Rank & Chi-square & d.f & Asymp. Sig. \\
\hline Institution & Available & 523 & 432.38 & 13.002 & 2 & 0.01 \\
Category & Not available & 130 & 104.48 & & & \\
& Don't know & 20 & 16.07 & & & \\
\hline Total & 671 & & & & \\
\hline
\end{tabular}

Based on the asymptotic significance $(\mathrm{p}$-value $=0.01$ ) value obtained from the Kruskall-Wallis test, the null hypothesis that tests on independence between institution category and availability of modern equipment was rejected. This rejection implied that availability of modern equipment and institution categories were dependent. The next question was whether usage of the available equipment/tools varied significantly from one institution to another. This called for a Chi-square test.

\subsection{Chi-Square Test on the Use of Modern Tools}

This test involved checking whether there was any significant relationship between an institution category and use of modern tools. The test yielded a $p$-value $=0.01$. Since the test was performed at $5 \%$ level of significance and the $p$-value was less than 0.05 ( $p$ value $<0.05)$, the null hypothesis was rejected. This implied that the use of modern equipment/tools depended on institution category. This study, therefore, not only found that availability of modern equipment/tools varied from one institution category to another, but also the extent of use of available equipment/tools and facilities in training.

While focusing on capacity in terms of training students, respondents were asked about adequacy of training tools and equipment. Specific equipment were identified and cross-tabulation between respondents, who 
said the equipment were available, and institution category was done. Output of this procedure was summarized in Table 2.

Table 2:- Adequacy of Training Tools and Equipment

\begin{tabular}{|c|c|c|c|c|c|}
\hline & \multicolumn{2}{|c|}{ Institution Category } & \multirow{2}{*}{$\begin{array}{c}\text { Chi- } \\
\text { square }\end{array}$} & \multirow[t]{2}{*}{ p-value } \\
\hline & & University & TVET & & \\
\hline \multirow{5}{*}{$\begin{array}{l}\text { Resource/ } \\
\text { Equipment } \\
\text { Adequacy }\end{array}$} & Hood/steam extractors & 64 & 19 & \multirow[t]{5}{*}{4.330} & \multirow[t]{5}{*}{0.012} \\
\hline & Small equipment/tools & 166 & 68 & & \\
\hline & Hand wash basins/sinks & 79 & 28 & & \\
\hline & Cookers/ovens & 175 & 59 & & \\
\hline & Working space/table tops & 148 & 47 & & \\
\hline \multicolumn{2}{|c|}{ Averages (\%) } & $126(50.6)$ & $44(37.2)$ & & \\
\hline
\end{tabular}

Table 2 revealed that adequacy of training tools and equipment was dependent on institution category. This was due to the observed p-value (0.012), which was less than 0.05 . Of interest was, however, availability of hand wash basins/sinks. Out of the 671 respondents, only 79 from Universities and 83 from TVET responded that hand wash basins/sinks were available for training. Hand wash basins and/or sinks are known to form a very crucial aspect of food safety and hygiene practices and therefore, all institutions that handled food production were expected to focus on improving hand wash sinks and basins.

\subsection{Testing of Hypothesis 3: Chi-Square Test on the Suitability and Capacity of Institutions}

In this case, the tested null hypothesis was formulated as:

$\mathrm{H}_{03}$ There is no significant difference in the capacity for the TVET and University hospitality schools in offering food safety and hygiene training.

This test aimed at examining whether the level of suitability and capacity of institutions could be associated with specific institutions. The test was, therefore, performed after running a cross-tabulation between institution category, level of suitability and capacity of institutions. When the test was done, the $p$-value was found to be 0.004 . This value was less than the 0.05 ( $p$ value $<0.05)$ and therefore the null hypothesis was rejected. The rejection led to a conclusion that there was a significant relationship between the institution categories and level of capacity of institutions in providing training on food safety and hygiene practices at 5 $\%$ level of significance. The finding, therefore, implied that different institutions had different levels of capacity of institutions in providing training on food safety and hygiene practices. These findings were consistent with the previously made observations about variations in availability and adequacy in training equipment/tools.

\subsection{T-Test: Test for Differences in the Level of Capacity in Institutions}

Having observed that there were variations from one institution category to another in terms of availability, adequacy and usage of training equipment/tools rendering the suitability and capacity of the institutions to also vary, the researcher performed a paired t-test to check whether the differences were significant. Output of this test was summarized in the table 3 .

Table 3:- One Sample T-test for Differences in the Level of Suitability and Capacity of Institutions

\begin{tabular}{|c|c|c|c|c|}
\hline & Mean & Std. Dev. & t-statistics & $p$-value \\
\hline Universities-TVET & 86.50 & 28.00 & 5.809 & .011 \\
\hline
\end{tabular}

The t-test output gave $p$-values $=0.011$ which was less than $0.05(0.011<0.05)$ and therefore the formulated null hypothesis was rejected. The rejection implied that there were statistically significant differences in capacity level of TVET and University hospitality schools in providing training on food safety and hygiene practices.

\section{Summary Of The Findings Of The Study}


The study also focused on the capacity of the institutions in providing training on food safety and hygienic practices. It looked at the availability of appropriate equipment, including mechanical, electrical, large and small basic equipment and tools available in the institutions. The findings revealed that in the two categories of institutions, equipment/tools in universities were relatively higher in number compared to the other categories. In addition, not all the available tools were modern. It was observed that only $78 \%$ of the available tools were modern while $19 \%$ were not. This finding revealed that there was underutilization of available facilities in the institutions. A summary of various aspects of capacity of institutions in providing training on food safety and hygienic practices and adopting proper hygienic practices revealed that universities had a high capacity $(63.5 \%)$ relative to the other categories. On the other hand, the lowest capacity level was observed in institutes of science and technology, which had $46.4 \%$.

The second step taken was to ascertain the capability of TVET and universities schools offering training in hospitality courses. The findings revealed that some institutions were well-prepared in terms of equipment and facilities, while the majority were not. Observation revealed that most of the workshops used, particularly in TVET institutions, were originally used for other purposes such as classrooms, home economics laboratory or were stores converted to production workshops. As a result, such institutions lacked basic equipment.

\section{Conclusions}

The study concluded that TIVET and Universities had inadequate facilities and resources required to offer food safety and hygiene training courses. This was evidence by the availability small workshop and limited facilities which could not cater for the available number of students taking the courses.

\section{Recommendations}

The study recommended ministry of education should to identify a monitoring team to visit hospitality training workshops to assess the capacity in terms of infrastructure, facilities and equipment to determine the level of requirement in every institution. This would pave way for the upgrading of the facilities to a level that they would offer adequate training to the enrolled students.

\section{References}

[1] Abegaz, M. (2007). Trade capacity building in agro-industry products for the establishment and proof of compliance with international market requirements. UNIDO, Vienna 3, 6-9.

[2] Acheson, D. (2011). Slides on food safety and legislation. Food Journal 102(6), 145-156. In Food Safety Modernization Act.

[3] Adams, M., \& Mortajemi, Y. (2003). African Cities (Abstract). Bulletin on Food Safety for Health Workers, Geneva, Switzerland. WHO, 21-22.

[4] Akonor, P. T., \& Akonor, M. A. (2013). Food Safety Knowledge: The case of Domestic Food Handlers in Ghana 3(3), 99-110.

[5] Anding, D. J. (2001). Self- reported changes in food safety behaviours among the food service employees: Impact of a retail food Safety education programme. Journal of Food Safety Science Education, 6, 72-76.

[6] Angelillo, N. M., Vigiani, L. Rizzo, A. B. (2000). Food handlers and food borne diseases. Knowledge attitude and reported behaviour in Italy. Journal of food pretection, 63 (3), $381-385$.

[7] Bertin, C. H. F. (2009). Hurdles at work: Perception of hospital food handlers. Human resources for health 7,63 .

[8] CDC (2004). Emerging Infectious Diseases Journal 18(3).

[9] CDC (2005). Foodborne illnesses. International Food Safety Consultancy.

[10] Clayton, D. A. \& Griffith, C. J. (2008). Efficacy of an extended theory of planned behaviour model for predicting caterers' hand hygiene practices. International Journal of Environmental Health Research 18(2), 83-98.

[11] Clayton, D. A., \& Griffith, C. J. (2004). Observation of food safety practices in catering using rotational analysis. British Food Journal 106(3), 211-227.

[12] Coleman, P., \& Roberts, A. (2005). Food hygiene training in the U.K: A time for change. Journal of Food Service Technology. 
[13] Douglas (2011). Hawaii lodging hospitality and food service. Expo 808, 261-340.

[14] Egan, M., Raats, M., Grubb, S., Eves A., Lumbers, L., Dean, M., Adams, M. (2007). A Review of food safety and food hygiene training studies in the commercial sector.

[15] Ehiri, J. E., Morris, G. P., \& Ewen, J. (1997). Evaluation of a food hygiene training course in Scotland. Food Control, 8, 137-147.

[16] Green, L. R. (2003). Behavioural sciences and food safety. Journal of environmental Health, 71(2) 47-49.

[17] Greene, S. K., Daly, E. $\quad$ R., Talbot, E. $\quad$ A., $\quad$ Demma, L. J., Holzbauer, S., \& Patel, N. J. (2005). Recurrent multistate outbreak of salmonella newport associated with tomatoes from contaminated fields. Epidemiology of Infection 2008; (136),157-165. DOIPubMed

[18] Griffith, C. J. (2001). Food safety in catering establishments. In J. M., Farber \& E. C. Todd (eds.). Safe Handling of Foods. Marcel Dekker, New York, (6) 235-246.

[19] Howells, A. D., Roberts, K. R., Shanklin, C. W., Pilling, V. K., Brannon, L. A. and Barrett, B. B. (2008). Restaurant employees' perceptions of barriers to three food safety practices. Journal of American Dietetic Association, 108, 1345-1349.

[20] Kaferstein, F. K. (2003). Food Safety: The fourth pillar in the strategy to prevent infant diarrhea. Bulletin of the WHO 81, 842-843.

[21] Knowles, T. (2002). Trends in food safety: Implications for European hotels. International Journal of Contemporary Hospitality Management, 13(4), 176 - 182.

[22] Legnani, P. (2004). Hygiene control of mass catering establishment. Microbiological monitoring of food and equipment. Food Control,15, 205-211.

[23] Mc Lauchlin, J., Grank, K.A., \& Little, C. L. (2007). Foodborne botulism in U. K. Journal of Public Health 28, 337-342.

[24] Mortlock, M. P., Peters, A. C., \& Griffith, C. (2009). A National Survey of Food Hygiene Training and qualification levels in the U. K. Food Industry. International Journal of Environmental Health 10, 111-123.

[25] Park, S. H., Kwak, T. K \& Chang, H. J. (2010). Evaluation of the Food Safety Training for Food Handlers in Restaurant Operations. Nutritional Research and Practice. 4(1), 58-68.

[26] Pragle, A. S., Harding, A. K., \& Mack, J. C. (2007). Food workers' perspective on hand washing behaviours and barriers in the restaurant environment. Journal of Environmental Health. 69(10), 27 32.

[27] Rangel J. M., Sparling, P. H., Crowe, C., Griffin, P. M., \& Swerdlow, D. (2005). Epidemiology of Escherichia Coli.

[28] Raymond, E. C., \& Griffith, C. J. (2006). Assessment of consumer food safety education provided by local authorities in the UK. British Journal 108(9), 732-753/www.emerald insight.com/journals.

[29] Rennie, D. M. (1999). Health education models and food hygiene education. The Journal of the Royal Society for the Promotion of Health, 119(2), $75-79$.

[30] Richardson, I. R. \& Stevens, A. M. (2003). Microbiological examination of ready-to-eat stuffing from retail premises in the North-East of England. The Get Stuffed survey. Journal of Applied Microbiology, 94, 733-737.

[31] Rodriguez, C. M., \& Gregory, S. (2005). Qualitative study of transfer of training of student employees in a service industry. Journal of Hospitality and Tourism Research, (1), 42-66.

[32] Sagoo, S. K., Little, C. L., \& Mitchell, R. T. (2003). Microbiological quality of open ready-to-eat salad vegetables: Effectiveness of food hygiene training of management. Journal of Public Health. 66(9), 21-25.

[33] Seaman, P., \& Eves, A. (2006). The Management of Food Safety - The role of food hygiene training in the U.K service Sector. International Journal of Hospitality Management, 25(2), 278-296.

[34] Sessional Paper (2005). Government of Kenya.

[35] Sneed, J., Strohbehn, C. V., \& Gilmore, S. A. (2004). Food Safety Practices and readiness to implement HACCP programs in assisted - living facilities in Iowa. Journal of the American Dietetic Association, 104,1678-1683.

[36] Toh, P. S., \& Bichenough, A., (2000). Food safety knowledge and attitude: Culture and environment impact on Hawkers in Malaysia. 
[37] WHO (2003). Evaluation of programmes to ensure food safety, guiding principles. Geneva: Switzerland.

[38] WHO (2007). Food Safety and Food-borne Illness. Fact Sheet 237, www.who.int/mediacentre/factsheets/fs237/en/www. who.int/entity/foodsafety/publication/consumer

[39] Yiannas, F. (2009). Food safety culture: Creating a behaviour- based food safety management system. Bentoville: Springer. 